\title{
Pre-analytical stability of 25-hydroxy vitamin D in human serum
}

\author{
Berna Bozkurt', Mujgan Ercan², Hayrullah Yazar³, Ozlem Hurmeydan ${ }^{4}$ \\ 'Department of Biochemistry, Ankara Etlik Zübeyde Hanım Training And Research Hospital, Ankara, Turkey \\ ${ }^{2}$ Department of Biochemistry, Yozgat Bozok University, Yozgat, Turkey \\ ${ }^{3}$ Department of Biochemistry, Sakarya University Training And Research Hospital, Sakarya, Turkey \\ ${ }^{4}$ Department of Biochemistry, Dr. Lütfi Kırdar Kartal Training And Research Haspital, Istanbul, Turkey
}

\begin{abstract}
Objectives: In this study, the effects of pre-analytical storage conditions on 25-hydroxy vitamin D [25(OH)D] samples were examined. The aim was to observe the relative effects of different temperature and time-related storage conditions on the stability of vitamin D.

Methods: Blood samples from 153 healthy individuals referred to Sakarya Training and Education Hospital polyclinics were stored under different conditions. Serum was obtained by centrifugation and 4 aliquots were stored. One aliquot was analyzed immediately after collection (0-hour sample) and accepted as the reference for the comparison of the other aliquots. Time intervals and different storage conditions for aliquots were categorized as Group 1: 0-hour measurement $(n=153)$, Group 2: 24 hours at $2-8^{\circ} \mathrm{C}(n=153)$, Group 3: about 2 months at $-20^{\circ} \mathrm{C}(n=153)$, and Group 4: 3 months at $-40^{\circ} \mathrm{C}(\mathrm{n}=153)$. Vitamin $\mathrm{D}$ analysis was performed using chemiluminescence in the biochemistry laboratory. Results: There was no statistical difference in $25(\mathrm{OH}) \mathrm{D}$ between the 0 -hour sample and the $2-8^{\circ} \mathrm{C},-20^{\circ} \mathrm{C}$, or $-40^{\circ} \mathrm{C}$ samples $(p=0.462, p=0.958, p=0.063$, respectively); $25(\mathrm{OH}) \mathrm{D}$ was stable under different storage conditions.

Conclusion: Vitamin $\mathrm{D}$ is an analyte that is generally not affected by preanalytical variables, and the storage conditions did not affect the acridinium ester magnetic particle chemiluminescence method used.
\end{abstract}

Keywords: Preanalytical stability, 25-hydroxy vitamin D, vitamin D analysis

$V^{2}$ itamin D is a fat-soluble vitamin that is involved in calcium and phosphorus homeostasis. Vitamin D naturally occurs in 2 forms: D2 (ergocalciferol), from plant sources, and D3 (cholecalciferol), produced in the skin with exposure to ultraviolet light and from animal sources. Both forms of vitamin D are prohormones that undergo hepatic hydroxylation to $25-\mathrm{OH}$ vitamin D2 [25(OH)D2] and 25-OH vitamin D3 [25(OH)D3] [1].

Vitamin D has several functions in cell growth, immunity, and metabolism. Vitamin D deficiency is associated with osteoporosis and osteomalacia in adults and rickets in children. Recent studies of the physiological effects of vitamin $D$ suggest it also has a role in autoimmune diseases, cancers, hypertension, multiple sclerosis, cognitive impairment, bipolar disorder, and schizophrenia [1-4]. The predominant circulating form is 25-hydroxyvitamin $\mathrm{D}[25(\mathrm{OH}) \mathrm{D}]$, and it is the most reliable indicator of vitamin D storage [5]. The half-life of $25(\mathrm{OH}) \mathrm{D}$ is approximately 20 days, and therefore, it is considered the best marker to reflect vitamin D condition (synthesis, uptake, and consumption). Vitamin D is mostly found as $25(\mathrm{OH}) \mathrm{D} 3$ in the blood, which is the main form of storage [6].

Vitamin D measurement is not a common test performed in every laboratory and samples are often shipped for analyte determination. Therefore, optimization of storage and transfer conditions is considered necessary to minimize pre-analytical errors. 
The aim of this study was to evaluate the effect of different time intervals and storage temperature conditions on samples to simulate circumstances in which they would not be run on the day of collection and be transported to an external laboratory.

\section{Materials and Methods}

The study was performed in the Sakarya Training and Research Hospital Biochemistry Department, in Sakarya, Turkey, between July and December 2014. A total of 153 individuals (125 female, 28 male) were included in the study. Subjects were healthy adults, with no known diagnosis of cancer, diabetes mellitus, cardiovascular disease, or osteoporosis. Information about the study was provided to all participants, and all completed an informed consent form. The study was conducted according to the principles of the Declaration of Helsinki and was approved by the Sakarya University Faculty of Medicine ethics committee (no.: 16.03.2015-3308). Venous blood was processed into 5-mL serum separator tubes with clot activator (BD Vacutainer; Becton Dickinson and Co., Franklin Lakes, NJ, USA). All collection tubes were centrifuged at $4000 \mathrm{xg}$ for 5 minutes in a refrigerated centrifuge after the serum samples had been at room temperature for 30 minutes to allow proper clot formation. After centrifugation, all of the serum samples were aliquoted into 4 vials. One aliquot was analyzed immediately after collection (0hour sample) and accepted as the reference for the comparison with the other aliquots. The time intervals and storage conditions for the aliquots were Group 1: 1 vial for 0-hour time measurement, Group 2: 24 hours at 2-8 ${ }^{\circ} \mathrm{C}$, Group 3: about 2 months at $-20^{\circ} \mathrm{C}$, and Group 4: 3 months at $-40^{\circ} \mathrm{C}$.

The level of $25(\mathrm{OH}) \mathrm{D}$ was determined using an automated acridinium ester magnetic particle chemiluminescence method on an IDS-ISYS analyzer and manufacturer reagents (Immunodiagnostic Systems, The Boldons, UK). Prior to determination of vitamin $\mathrm{D}$ concentration for each study period, the device was calibrated with the original calibrator and verified with internal quality control serum (IDS-ISYS 25-Hidroxy Vitamin D Control Set; Immunodiagnostic Systems, The Boldons, UK). All samples were run with reagents of the same lot number. Internal quality control samples were included in the assay run, and intraassay coefficients of variation (CV) values were obtained from the measurements. The intra-assay CV was $7.66 \%, 5.81 \%$, and $4.92 \%$, with target values of $19.5 \mathrm{ng} / \mathrm{mL}, 33.4 \mathrm{ng} / \mathrm{mL}$, and 66.0 $\mathrm{ng} / \mathrm{mL}$ (IDS-ISYS 25-Hydroxy Vitamin D Control L, M, and H; Immunodiagnostic Systems, The Boldons, UK ).

The specimens were exposed to standard lighting conditions in the laboratory and there were no changes in the lighting conditions throughout the study. As soon as blood was drawn from the patients, it was transferred without being covered with laboratory foil and was exposed to direct daylight.

\section{Statistical Analysis}

Statistical data were processed using PASW Statistics for Windows, Version 18 (SPSS Inc., Chicago, IL, USA). The conformity

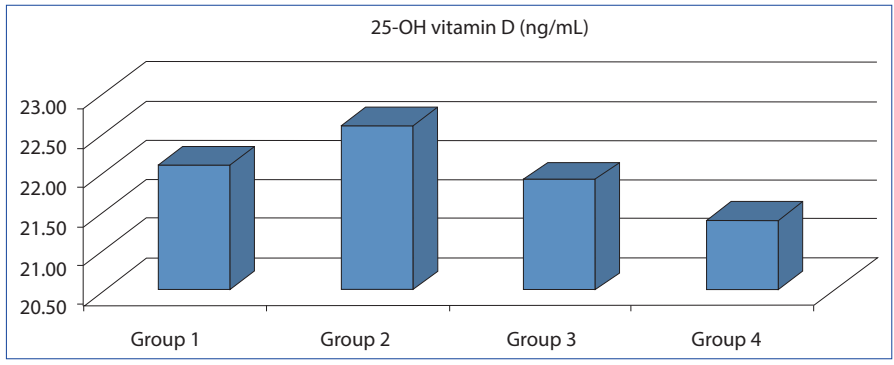

Figure 1. Median 25-hydroxyvitamin D concentration of serum samples stored in different conditions. Group 1: analyzed immediately after collection, Group 2: stored at $2-8^{\circ} \mathrm{C}$ for 24 hours, Group 3: stored at $-20^{\circ} \mathrm{C}$ for 2 months, and Group 4 : stored at $-40^{\circ} \mathrm{C}$ for 3 months.

of variables to normal distribution was tested with the Kolmogorov-Smirnov test. The descriptive statistics of continuous variables were expressed as mean $\pm \mathrm{SD}$ or median (minmax). In the tube group analysis, the presence of a statistically significant difference between the groups was examined with a paired t-test for parametric and the Wilcoxon signed rank test for nonparametric continuous variables. $\mathrm{P}$ values $<0.05$ were considered statistically significant.

\section{Results}

In this study, different storage conditions for samples were investigated to evaluate the effect on the stability of vitamin $\mathrm{D}$ : 24 hours at $2-8^{\circ} \mathrm{C}$, about 2 months at $-20^{\circ} \mathrm{C}$, and 3 months at $-40^{\circ} \mathrm{C}$.

The concentration of $25(\mathrm{OH}) \mathrm{D}$ did not demonstrate a significant difference at the investigated time and temperature intervals. In the 0 -hour sample, the $2-8^{\circ} \mathrm{C},-20^{\circ} \mathrm{C}$, and the $-40^{\circ} \mathrm{C}$ sample, the median level (minumum-maximum) of $25(\mathrm{OH}) \mathrm{D}$ was similar: $22.10 \mathrm{ng} / \mathrm{mL}$ (7-107.7 ng/mL), $22.6 \mathrm{ng} / \mathrm{mL}$ (7-111 $\mathrm{ng} / \mathrm{mL}), 21.9 \mathrm{ng} / \mathrm{mL}(7-109.3 \mathrm{ng} / \mathrm{mL})$, and $21.4 \mathrm{ng} / \mathrm{mL}$ (7-119.3 $\mathrm{ng} / \mathrm{mL}$ ), respectively. The measured values by group are provided in graph form in Figure 1.

There was no significant statistical difference between the 0 -hour sample $25(\mathrm{OH}) \mathrm{D}$ and the $2-8^{\circ} \mathrm{C},-20^{\circ} \mathrm{C}$, and the $-40^{\circ} \mathrm{C}$ $25(\mathrm{OH}) \mathrm{D}$ levels $(\mathrm{p}=0.462, \mathrm{p}=0.958, \mathrm{p}=0.063$, respectively).

\section{Discussion}

Information about the preanalytical stability of $25(\mathrm{OH}) \mathrm{D} 3$ in human blood is hard to find. Medical laboratory sample-handling guidelines currently require freezing the sample and protecting it from artificial light and repeated freeze and thaw cycles. On the other hand, food industries have reported very high durability of $25(\mathrm{OH}) \mathrm{D} 3$ in natural matrices, such as fat and milk.

Our results revealed no significant difference in $25(\mathrm{OH}) \mathrm{D}$ with regard to time interval and temperature of storage. According to this stability study, $25(\mathrm{OH}) \mathrm{D}$ levels were stable for 24 hours at $2-8^{\circ} \mathrm{C}$, about 2 months at $-20^{\circ} \mathrm{C}$, and 3 months at $-40^{\circ} \mathrm{C}$. 
Other studies have indicated that vitamin D was a stable analyte under common storage conditions [7-11]. Some authors investigated the freeze-thaw process and whether the samples were affected by sunlight or artificial light.

Wielders et al. [7] examined blood samples from 8 individuals at $6^{\circ} \mathrm{C}$, at room temperature protected from light, and at room temperature exposed to artificial light. They also analyzed the effect of 4 freeze-thaw cycles. The level of 25(OH)D3 was measured with a commercial kit using antibody-based methods (Cobas E601 analyzer and 25-OH vitamin D3 assay; Roche Diagnostics, Basel, Switzerland). In that study, it was reported that serum vitamin $D$ levels did not change at $4^{\circ} \mathrm{C}$ for at least 7 days and up to 4 freeze-thaw cycles. The authors reported the stability of vitamin D at room temperature as "solid as a rock" [7]. In a similar study, vitamin D levels were measured with a binding method and 11 freeze-thaw processes, and no significant change was detected in the measurement results [8].

In a study conducted by Remijn et al. [9], $200 \mathrm{~mL}$ of blood was collected from a single donor. After centrifugation of the blood sample, the serum was removed and stored at $-20^{\circ} \mathrm{C}$. Portions were then subjected to various conditions, including as many as 5 freeze-thaw cycles and various exposures to fluorescent light, direct sunlight, and temperature. Vitamin D was analyzed $[25(\mathrm{OH}) \mathrm{D} 3$ and D2) using high-performance liquid chromatography-tandem mass spectrometry. Unlike other studies, they found that exposure to sunlight reduced the vitamin D level. In our study, there were no changes to the lighting conditions of the laboratory throughout the study. We did not investigate the effect of direct sunlight or artificial light.

Colak et al.[10], investigated common storage conditions and found vitamin $D$ to be a stable analyte. Their study was the first to evaluate the effect of centrifugation temperature on vitamin $\mathrm{D}$ concentration and no difference was observed between a refrigerated centrifuge $\left(2-8^{\circ} \mathrm{C}\right)$ and a centrifuge at room temperature. They investigated both serum and plasma samples, and the results indicated that sample type did not affect stability.

A study by Bodnar et al. [11] compared 25(OH)D by race and season in sera frozen for $\geq 40$ years with sera frozen for $\leq 2$ years to determine whether $25(\mathrm{OH}) \mathrm{D}$ is stable enough to test vitamin D-related hypotheses. They found no significant difference between sera frozen for $\geq 40$ years with sera frozen for $\leq 2$ years.

According to experts, vitamin D remains attached to the protein in complete blood and protects stability when there is no separation [12]. In our study, storage temperature and time variations led to no significant statistical difference in $25(\mathrm{OH})$ D level compared to the 0 -hour sample 25(OH)D.

Vitamin $D$ is a secosteroid vitamin structure; the 9-10 carboncarbon bond of the $B$ ring is broken. The cis-triene structure is located in the center of the chemical structure of vitamin D. This unique structure of vitamin D causes it to become sensitive to oxidation, and changes induced by factors such ultraviolet light and free radicals [13].
Some studies have found differences in 25(OH)D levels based on storage conditions. Drammeh et al. [14] stored 35 whole blood samples at either $32^{\circ} \mathrm{C}$ for up to 3 days before serum separation or they were centrifuged within 2 hours of collection. The vitamin $D$ level was determined by radioimmunoassay (RIA), and it was found that delayed freezing of serum led to a $7 \%$ increase in the vitamin D level. Thirty-five patients included in a study conducted by Akgol et al. [15] provided blood samples separated into 3 separate tubes. Group 1 samples were incubated at room temperature, Group 2 at $2-8^{\circ} \mathrm{C}$ and Group 3 at $-80^{\circ} \mathrm{C}$. The vitamin D results of Group 3 were significantly higher than those of Group 1 and Group 2 ( $p<0.001$ for both). There was no statistically significant difference between Group 1 and Group 2 vitamin D results ( $p=0.051)$. Decomposing molecular structure was thought to be the cause of the low values in Group 1 and Group 2 in this study.

\section{Conclusion}

In this study, the effects on 25(OH)D of different time intervals and storage temperature conditions were examined. Samples were stored at $2-8^{\circ} \mathrm{C}$ hours for 24 hours, at $-20^{\circ} \mathrm{C}$ for about 2 months, and at $-40^{\circ} \mathrm{C} 3$ months, and there was no significant statistical differences in $25(\mathrm{OH}) \mathrm{D}$ level compared with the level of the 0-hour sample. One of the limitations of our study is we do not know whether the samples were affected by direct sunlight. As soon as blood was taken from the patients, it was transferred to the laboratory, but we could have assessed the effect of direct sunlight on samples with 1 tube that was open, while another was wrapped with laboratory foil. Also, freezethaw processing was not investigated in the present study. In conclusion, our data confirmed that vitamin $\mathrm{D}$ is an analyte that is generally less affected by preanalytical variables, the storage conditions applied had no effect on the acridinium ester magnetic particle chemiluminescence method used.

\section{Conflict of interest: None declared.}

Peer-review: Externally peer-reviewed.

Authorship contributions: Concept - B.B.; Design - B.B.; Supervision - B.B.; Fundings - B.B.; Materials - B.B.; Data collection \&/or processing - Ö.H.; Analysis and/or interpretation - M.E.; Literature search - H.Y.; Writing - B.B.; Critical review - B.B.

\section{References}

1. Kushnir MM, Ray JA, Rockwood AL, Roberts WL, La'ulu SL, Whittington JE, et al. Rapid analysis of 25-hydroxyvitamin $D(2)$ and $D(3)$ by liquid chromatography-tandem mass spectrometry and association of vitamin $\mathrm{D}$ and parathyroid hormone concentrations in healthy adults. Am J Clin Pathol 2010;134:148-56. [CrossRef]

2. Boerman R, Cohen D, Schulte PF, Nugter A. Prevalence of Vitamin D Deficiency in Adult Outpatients With Bipolar Disorder or Schizophrenia. J Clin Psychopharmacol 2016;36(6):588-92.

3. Camacho PM, Petak SM, Binkley N, Clarke BL, Harris ST, 
Hurley DL, et al. American association of clinical endocrinologists and American college of endocrinology clinical practice guidelines for the diagnosis and treatment of postmenopausal osteoporosis - 2016-executive summary. Endocr Pract 2016;22:1111-8. [CrossRef]

4. Almurdhi MM, Reeves ND, Bowling FL, Boulton AJ, Jeziorska M, Malik RA. Reduced Lower-Limb Muscle Strength and Volume in Patients With Type 2 Diabetes in Relation to Neuropathy, Intramuscular Fat, and Vitamin D Levels. Diabetes Care 2016;39:441-7. [CrossRef]

5. Davenport ML, Uckun A, Calikoglu AS. Pediatrician patterns of prescribing vitamin supplementation for infants: do they contribute to rickets? Pediatrics 2004;113:179-80.

6. Vieth R. Vitamin D supplementation, 25-hydroxyvitamin D concentrations, and safety. Am J Clin Nutr 1999;69:842-56.

7. Wielders JP, Wijnberg FA. Preanalytical stability of $25(\mathrm{OH})$-vitamin D3 in human blood or serum at room temperature: solid as a rock. Clin Chem 2009;55:1584-5. [CrossRef]

8. Lissner D, Mason RS, Posen S. Stability of vitamin D metabolites in human blood serum and plasma. Clin Chem 1981;27:773-4.

9. Lewis JG, Elder PA. Serum 25-OH vitamin D2 and D3 are stable under exaggerated conditions. Clin Chem 2008;54:1931-2.

10. Colak A, Toprak B, Dogan N, Ustuner F. Effect of sample type, centrifugation and storage conditions on vitamin $D$ concentration. Biochem Med (Zagreb) 2013;23:321-5. [CrossRef]

11. Bodnar LM, Catov JM, Wisner KL, Klebanoff MA. Racial and seasonal differences in 25-hydroxyvitamin $D$ detected in maternal sera frozen for over 40 years. Br J Nutr 2009;101:278-84.

12. Kleerekoper M, Schleicher RL, Eisman J, Bouillon R, Singh RJ, Holick MF. Clinical applications for vitamin D assays: what is known and what is wished for. Clin Chem 2011;57:1227-32.

13. Armas LA, Hollis BW, Heaney RP. Vitamin D2 is much less effective than vitamin D3 in humans. J Clin Endocrinol Metab 2004;89:5387-91. [CrossRef]

14. Drammeh BS, Schleicher RL, Pfeiffer CM, Jain RB, Zhang M, Nguyen PH. Effects of delayed sample processing and freezing on serum concentrations of selected nutritional indicators. Clin Chem 2008;54:1883-91. [CrossRef]

15. Akgol E, Abuşoğlu S, Çelik HT, Züngün C Sezer S, Turhan T, et al. Sample stability in liquid chromatography tandem mass spectrometry analysis of vitamin D. Journal of Turkish Clinical Biochemistry 2013;11:67-72. 